\title{
Public Acceptance of ITER-Tokamak Fusion Power
}

\author{
Robert L. Hirsch and Roger H. Bezdek
}

\section{ABSTRACT}

One of the U.S. Electric Power Research Institute's criteria for practical fusion power is public acceptance. In this analysis we consider the potential public acceptance of ITER-tokamak fusion power. Because ITER-like reactors are not likely to be commercially ready before mid-century, a forecast of public acceptance is very difficult. We break "the public" down into four entities: 1) Rank and file consumers, 2) Governments [local, state, \& federal including regulators], 3) NGOs including environmental groups, and 4) Electric utilities. We assert that ITER-tokamaks will be evaluated in the context of fission power because both are nuclear processes. We observe that ITER-tokamak fusion will present radioactive hazards and be extremely expensive. Three possible futures for fission nuclear mid-century are: 1) full acceptance, 2) middling acceptance, and 3) rejection. If fission power is accepted mid-century, then ITER-tokamak fusion stands the best chance of being publicly acceptable, its largest drawback being very high cost. If fission power is of middling acceptance, then ITER-tokamak fusion might be marginally more acceptable because of its much shorter life radioactive waste. If fission power is unacceptable, then ITER-tokamak fusion acceptance will be very difficult.

Keywords: Commercial fusion, fusion, ITER, ITER-tokamak power plant capital cost, public acceptance.

\section{INTRODUCTION}

The goal of fusion research is to develop an attractive electric power source based on fusion reactions. In 1994 the Electric Power Research Institute (EPRI), the research arm of the U.S. electric utility industry, outlined three criteria important for a commercially acceptable fusion power plant: competitive electric power cost, regulatory simplicity, and public acceptance [1]. In the following we consider the likely U.S. public acceptance of ITER-tokamak fusion power [2].

According to EPRI, "public acceptance and customer satisfaction will be essential to the commercial success of future fusion power plants. A positive public perception can be best achieved by maximizing fusion power's environmental attractiveness, economy of power production, and safety [2].

If the current ITER experiment is a success, it has been suggested that it will be followed by a demonstration power plant to operate around mid-century [3]. To forecast public acceptance that far into the future, we consider ITERtokamak fusion power in today's context and then extrapolate into three possible futures. We break down the U.S. public into the following entities:

1) Rank and file consumers,

2) Governments (local, state, \& federal including regulators),

3) NGOs including environmental groups, and

4) Electric utilities and their public utility commissions (PUC's)

We then consider the likely attitudes of each towards ITERtokamak fusion power. We believe that all of the "publics" will consider ITER-tokamak fusion power in the framework of fission power, because fusion is also a nuclear process. It would be illogical to think of fusion fitting into any other category - it is not renewable in the strict sense, and it is certainly not a fossil fuel technology.

\section{Characteristics OF ITER-Tokamak Fusion POWer}

The lay-level public might view this form of electric power production as follows:

- It is a nuclear process, like the ones that power the sun and the stars.

- It has a low-cost fuel supply.

- It involves a high level of radioactivity during operation and has a large amount of radioactive waste that dies out much faster than the waste from fission reactors [4].

- There is no chance for a nuclear runaway, but there is the remote possibility of an explosion associated with a malfunction of the huge magnets.

- It seems to be extremely expensive, as explained below.

\section{Current Views of Various Public Entities}

\section{A. Introduction}

Of the various public entities, environmental groups have been the most vocal on energy matters in recent years, so we begin with their current positions. 


\section{B. Environmental Groups Positions on Fission Nuclear Power}

Environmentalists have generally been negative to nuclear power, often vigorously. A sampling of their positions follows:

- Climate Action Network: "Nuclear power is socially, environmentally and economically unsustainable" [5].

- Environmental Defense Fund: "EDF is actively seeking to replace nuclear plants around the country..." [6].

- Friends of the Earth: "Nuclear power is too expensive, too dangerous and dirty, and takes too long to deploy..." [7].

- Green Party: "The Green Party calls for the early retirement of nuclear power reactors as soon as possible..." [8].

- Greenpeace: "Nuclear power is dirty, dangerous and expensive." [9].

- NRDC: “...natural hazards such as hurricanes and earthquakes, human error, mechanical failure, or design flaws can still trigger the release of radioactive contamination." [10].

- Sierra Club: "The Sierra Club opposes the licensing, construction and operation of new nuclear reactors ... pending: resolution of the significant safety problems inherent in reactor operation, disposal of spent fuels, and possible diversion of nuclear materials capable of use in weapons manufacture." [11].

- World Wildlife Fund: "Nuclear is an unethical and expensive option (that) produces dangerous waste that remains highly toxic for thousands of years. (It) can also be used to produce nuclear weapons." [12].

One organization that is positive to nuclear is The Nature Conservancy, which favors "... increasing nuclear energy to one third of total energy output." [13]. Note that some softening in the hard views of environmentalists against fusion in the future is conceivable due to their feeling of urgency of addressing climate change [14].

\section{Environmental Groups Positions on Fusion Power}

We found only three U.S. groups commenting on fusion. Greenpeace has strongly condemned investment in the International ITER Fusion Project, claiming, "The money spent on ITER should instead be spent on renewables." [9]. The Sierra Club noted that "the dangers posed by the probable releases of tritium used by fusion plants, the problems with decommissioning these plants, and their high costs lead the Sierra Club to believe that the development of fusion reactors to generate electricity should not be pursued at this time." [11]. The Green Party also specifically opposes nuclear fusion [8]. The paucity of comment on fusion is related to the fact that fusion is not now a commercial option.

\section{Discussion}

Since fission nuclear power is a current reality, it is not surprising that environmental groups would develop explicit positions on the option, citing what they consider to be the most significant negatives. Similar negatives are likely to apply to ITER-tokamak fusion power:

1. Cost.
2. Safety, including potential to release radioactive materials, sensitivity to hurricanes and earthquakes, human error, technological failure, and design flaws.

3. Radioactive waste.

4. Time to deploy.

5. Potential to produce materials for nuclear weapons.

\section{E. Rank and File Consumers Positions}

Rank and file consumers in general do not seem to care much about electric power production technologies with the following exceptions:

1) When a new power plant is to be located close to where they live,

2) When they learn that one or more proposed new power plants are likely to significantly increase their electric bills,

3) When they are convinced, major change is needed.

Rate increases of $2,3,4$, or $5 \%$ often generate public outcries. At the present time, the primary driver for change is global climate concerns. In that regard, renewable technologies are typically favored. Those members of the public who have very strong feelings on specific technologies are likely to affiliate themselves with an environmental organization or other special interest group.

Nuclear fission energy has been a subject of public polling for some time. A number of recent polls in the U.S. have indicated around $50 \%$ pro and con [15]-[17].

The rank-and-file public is often curious about what something new might promise, so fusion is often of interest. We found one interesting public survey on fusion in Europe [18], which among other things indicated the following:

- About $50 \%$ of the respondents had heard about fusion energy.

- $\quad 36 \%$ considered fusion energy as "important" or "very important" and 40\% as "somewhat important."

Of course, there is no way of knowing if this or any other recent survey would be of any relevance at mid-century.

\section{F. Government Positions}

The U.S. federal government has been involved in fission electric power in a variety of ways since the Second World War: regulator of plant construction and operation; manager of nuclear waste transportation and disposal; manager of fuel enrichment; source of research funding for relevant research; etc. State governments are involved in fission nuclear plant siting and regulation of electric utilities within their borders. This is a complex and extensive subject beyond the scope of these discussions.

With respect to fusion energy, the federal government is the primary supporter of related research. States have had little interest in fusion over the past several decades.

\section{G. Electric Utilities Positions}

When it comes to adding new power plants or equipment to their systems, utilities first apply for state regulatory approval to roll related costs into their rate bases. For example, the State of Virginia recently enacted a zero-carbon emission law, and the local electric utility, Dominion Energy, responded with a proposal to satisfy that mandate using primarily offshore wind. The related increase in rates would amount to $40 \%$ over 15 years, providing the utility with a dramatic increase in profits [19]. Recently in Colorado, Xcel 
was allowed to invest $\$ 1.6$ billion in renewables and batteries and recoup the investments through rate increases [20].

From time-to-time personnel in the U.S. federal government have sought utility interest and support for fusion, but generally the response has been tepid, primarily because utility concerns are relatively near-term oriented.

\section{THE LiKely CAPITAL COSTS OF AN ITER-TOKAMAK POWER PLANT}

\section{A. ITER-Tokamak Reactor Studies}

One of the first comprehensive conceptual designs for a tokamak fusion power plant was performed at the University of Wisconsin in the early 1970s [21]. It suggested that overall plant costs could be $\$ 900-1000$ per $\mathrm{kWe}$ and commented that "it is encouraging that these preliminary estimates ... are not particularly out of line with first generation fission reactors." At the time it was recognized that those estimates would increase over time, as all such early estimates typically do. However, because the study was so comprehensive, it was hoped that the escalation would be modest.

Other reactor studies have taken place since the early 1970s. For example, in 2004 an analysis of an advanced tokamak power reactor found that the cost of electricity for a 1-1.5 GWe advanced tokamak power plant would be roughly comparable with the cost of electricity from a nuclear reactor [22]. Yet another study concluded "The cost of fusion electricity is likely to be comparable with that from other environmentally responsible sources of electricity generation." [23].

On the other hand, a comparison of an early embodiment of ITER with the core of an AP 600 fission reactor in the early 1990s indicated a mass difference of over a factor of 60 [24]. Part of the reason for the difference is the large open space needed for the high-volume fusion plasma and the large volume of moderator-heat transfer blanket that surrounds the plasma and is required to capture fusion neutron energy and particles and to shield the cryogenic superconducting magnets. A useful rule of thumb in engineering practice is that a rough comparison of capital costs of generally similar technologies can be obtained by considering the relative mass of the materials of construction for systems of similar capabilities. Thus, a huge disparity in likely core cost was indicated.

\section{B. ITER Capital Cost}

Here we wanted to estimate the likely cost of an ITER tokamak power reactor based on the ITER experience. This is difficult because a number of countries are involved in ITER construction, and each is responsible for the procurement of in-kind hardware within its own boundaries with its own currency. Accordingly, the ITER organization has maintained that an estimate for the cost of ITER construction "into a single currency is not relevant." [2]. On the other hand, the Director General of the ITER organization has publicly maintained that the ITER's overall construction cost is in the range of 20 billion Euros (roughly $\$ 22$ billion) [25].

The U.S. is committed to providing $9 \%$ of the ITER construction cost, and U.S. federal budget processes require specific numbers. According to the U.S. General Accountability Office (GAO), the full U.S. ITER project cost increased from roughly $\$ 1.1$ billion in 2005 to $\$ 3.9$ billion in 2013 [26]. At $9 \%$ of total costs, total ITER cost would have been roughly $\$ 11$ billion in 2005 and roughly $\$ 40$ billion in 2013 [25]. Expressed in constant 2019 dollars, this is currently about $\$ 44.2$ billion.

More recently the DOE FY2021 fusion budget request asserted that the estimated total U.S. project cost will be in the range of $\$ 4.7 \mathrm{~B}$ to $\$ 6.5 \mathrm{~B}$, which would roughly translate to a total a total cost in the range of $\$ 50-\$ 70$ billion. However, this estimate includes over a decade of ITER operations, so it represents more than just capital cost. The DOE document also indicates the cost of construction to first plasma in 2025 will be $\$ 2.5$ billion, which would translate to a total capital cost of roughly $\$ 28$ billion. First plasma will be in hydrogen, and additional upgrades to operate on DT could add additional capital cost, but to our knowledge that increment has not been specified. This illustrates a logical inconsistency, namely that a committed fraction of total construction costs implies the existence of an estimate of total cost, which the ITER organization maintains is unknowable.

Some analysts have concluded that fusion simply cannot be economically competitive. Thus, as stated by Jassby, "A corollary of extraordinarily high and irreducible operating costs is that the capital cost of a fusion reactor must be close to zero for economic competitiveness!" [27].

\section{Rough Capital Cost Estimate for an ITER-Tokamak \\ Power Reactor Based on the Cost of ITER}

It is one thing to undertake an analysis in the absence of relevant, large-scale hardware and quite another to extrapolate cost from an actual large-scale facility. In an effort to develop a rough capital cost estimate for an ITERtokamak power plant based on the ITER project, we approached the problem as follows.

First, we observed that an ITER-tokamak reactor is in effect an electric power amplifier, because it amplifies the input electrical power to the plasma heaters via fusion energy release, yielding a much higher power output.

Second, we assumed ITER to be prototypical of a power plant reactor core, because it is to be followed by a demonstration reactor in some instances [3].

Third, we assumed the ITER experiment meets its design targets of $500 \mathrm{MW}$ thermal output and a thermal energy gain of a factor of ten. Note that if ITER were coupled to thermalto-electric conversion machinery at $40 \%$ efficiency, it would produce $200 \mathrm{MW}$ electric.

Fourth, we assumed that plasma heating devices deliver $50 \%$ of their electric power input to the plasma. For the ITER experiment that would require $100 \mathrm{MW}$ of electrical power input $(50 \mathrm{MW}$ thermal $/ 0.5=100)$. The resultant power plant would then produce $100 \mathrm{MW}$ electric net for an electric power gain of a factor of one, which is markedly different than a thermal energy gain of ten.

Fifth, we assumed that the total ITER capital cost to the stage of full DT operation to be $\$ 30$ billion, an escalation from Bigot's recent initial capital cost estimate [28].

Finally, we assumed major advancements in ITERtokamak operations and technology before the power plant stage, so an ITER-like $500 \mathrm{MW}$ electrical reactor would have 
an electric power gain of ten, rather than one, an assumption we considered to be generous.

On this basis our ITER-like power plant would cost roughly $\$ 60,000 / \mathrm{kW}$ electrical. In so doing, we ignored a number of factors including the cost of thermal to electric power energy conversion machinery (which ITER does not have), a containment envelope that will surely be required by regulators (which ITER does not have) [28], more extensive hot cells, a larger array of robotics and maintenance equipment, spare superconducting coils, a complete set of blanket replacement modules, radioactive dust management and disposal equipment, energy storage/generation for startup, energy storage for makeup power between pulses, regulatory requirements as yet undefined, and tritium inventory for startup and fault conditions.

The estimated cost of a fission nuclear power plant in the U.S. is in the range of $\$ 5,000-\$ 8,000$ per kWe [29]. Two nuclear power plants are under construction in the U.S. at the present time. They are Alvin W. Vogtle Units $3 \& 4$. Their estimated capital cost is $\$ 25$ billion for a power output of $2500 \mathrm{MWe}$, which translates to $\$ 10,000$ per kWe [30].

Our rough calculation concludes that the capital cost of an ITER tokamak fusion power plant might be roughly a factor of 5-10 times more expensive than a roughly comparable fission reactor. If our rough cost comparison yielded a factor of two for instance, a cost inferiority / superiority conclusion would not be justified. However, because the comparison is so stark, it would seem prudent to be extremely concerned about the likely large comparative cost of an ITER tokamak power reactor compared to a fission power plant. This is especially true because many feel that, at least in the U.S., new fission power plants are currently too expensive to be economically competitive.

\section{The Capital Costs of Early Fission Nuclear Power Plants}

Not surprisingly, the early nuclear fission power plants were more expensive per unit of power output than later units. There is debate over whether Shippingport or Yankee Rowe was the world's first commercial nuclear fission power station, so we consider both.

Shippingport came on-line in 1958 at a capital cost of $\$ 72.5$ million [31]. Converting 1958 dollars to 2019 dollars using the U.S. Bureau of Economic Analysis (BEA) Implicit Price Deflator (IPD) indicates a capital cost of about $\$ 503$ million in 2019 dollars. Shippingport was rated at $68 \mathrm{MWe}$, so its capital cost was roughly $\$ 7.4$ million/MWe in 2019 dollars. When it came on-line, Shippingport was judged to be too expensive to be commercially viable.

Yankee Rowe came on-line in 1960 at a capital cost of $\$ 45$ million [32]. Converting 1960 dollars to 2019 dollars using the BEA IPD deflator indicates a capital cost of roughly $\$ 306$ million. Yankee Rowe was rated at $185 \mathrm{MWe}$, so its capital cost was about $\$ 1.65$ million/MWe in 2019 dollars. When it came on-line, Yankee Rowe was also judged to be too expensive to be commercially competitive. However, subsequent increases in the cost of fossil fuels eventually rendered it commercially feasible.

Thus, our estimated capital cost of an early ITER-tokamak power plant is roughly:

- 10-20X the actual capital cost of Shippingport

\section{- $\quad 40-80 X$ the actual capital cost of Yankee Rowe}

So, our hypothetical ITER-tokamak power plant is much more expensive than early U.S. nuclear reactors. As noted, comparison with the costs of new U.S. fission reactors indicates that the ITER is 5-10 times more expensive.

\section{E. Comparison of ITER-Tokamak Plant Capital Cost with Other Technologies}

How does our ITER-tokamak power plant capital cost compare to the cost of potential current alternatives? The potentially viable alternatives are renewables, natural gas, and coal.

Virginia has recently approved massive offshore wind turbines. They would be 2,600 MW with an estimated cost of about $\$ 8$ billion [19]. This is about $\$ 3.1$ million/MW excluding the costs of the backup power required.

Natural gas IGCC would cost about $\$ 820$ thousand/MWe [33]. Natural gas IGCC with CCUS (carbon capture, utilization, and storage) would cost roughly $\$ 1.6$ million/MWe [33]. Supercritical Coal would cost roughly \$2.2 million/MWe [33]. Supercritical Coal with CCUS would cost roughly $\$ 3.8$ million/MWe [33].

Thus, the estimated capital cost of an ITER-tokamak power plant is roughly:

- $20-40 X$ the capital cost of offshore wind -- excluding the cost of backup power

- $70-140 X$ the capital cost of a natural gas IGCC plant

- 30-60X the capital cost of natural gas IGCC with CCUS

- 20-40X the capital cost of supercritical coal

- 20-40X the capital cost of supercritical coal with CCUS Note that these cost comparisons are even more unfavorable to an ITER-tokamak power plant if very long periods are required to change out internals due to radiation damage and other material degradations, which could reduce plant availability by $25 \%$ or more [34]. This would also require $100 \%$ dispatchable backup power.

\section{CONCLUSION}

We believe that fusion power will be naturally coupled with fission nuclear power in the public's consideration of ITER-tokamak electric power, simply because both are nuclear processes, and it would be illogical to place it in any other electric power production category. Accordingly, when ITER-tokamak fusion power might be ready for commercial adoption around mid-century, it will be considered in conjunction with public attitudes towards fission nuclear power at that time.

Mid-century public attitudes towards fission power will be a function of unknowable variables, so we approach the ITER-tokamak power acceptance problem via consideration of three possible public attitudes towards fission power at mid-century:

1) full acceptance,

2) middling acceptance,

3) rejection.

From the foregoing the defining characteristics of ITERtokamak fusion power will likely be as follows:

- Its low-cost fuel supply.

- Its high level of radioactivity during operation 
- Its large amount of radioactive waste that dies out much faster than the waste from fission reactors.

- While there is no chance for a nuclear runaway in an ITER-like power plant, there is the remote possibility of an explosion associated with a major fault in the magnets.

- It is likely to be extremely expensive.

If fission power is acceptable at mid-century, ITERtokamak power will stand the best chance of public acceptance because of the much shorter decay time of its nuclear waste. It will be disadvantaged because of its likely much higher capital cost. Electric utilities might accept ITERtokamak fusion power if its high costs can be rolled into their rate base. If the lay-level public and PUCs were concerned about the much higher power costs, ITER-tokamak power would likely be rejected.

If fission power has middling acceptance at mid-century, the basis will have to be known before an evaluation of the public acceptance of ITER-tokamak power could be determined. If the long life of fission nuclear waste is the primary determinate, there may be a small chance that ITERtokamak power might be acceptable despite its much higher cost.

Finally, if fission power is rejected at mid-century, again the basis will have to be known before an evaluation of the public acceptance of ITER-tokamak power can be determined, but it seems much less likely that it will be publicly acceptable.

\section{REFERENCES}

[1] J. Kaslow, M. Brown, R. Hirsch, J. McCann, D. McCloud, B. Muston, and B. Snow, "Criteria for practical fusion power systems: Report from the EPRI fusion panel," Journal of Fusion Energy 13(2), 181-183, 1994.

[2] www.iter.org.

[3] M. Barbarino, "Charting the International Roadmap to a Demonstration Fusion Power Plant," IAEA May 11, 2018.

[4] www.iter.org/mach/safety.

[5] “A Sustainable Energy World Without Nuclear Power," Climate Action Network March 30, 2015.

[6] "Environmental Defense Fund (EDF)," Env. Progress September 12, 2019.

[7] "Nuclear energy: our position," Friends of the Earth 27 November 2017.

[8] Green Party U.S. Ecological Sustainability. https://www.gp.org/ecological_sustainability_2016.

[9] Nuclear Energy. Greenpeace. https:/www.greenpeace.org/usa/globalwarming/issues/nuclear/.

[10] “Nuclear Power 101," NRDC May 14, 2020.

[11] “Nuclear Power," Sierra Club November 15, 1986.

[12] The Energy Report. $100 \%$ Renewable Energy by 2050. https://c402277.ssl.cf1.rackcdn.com/publications/384/files/original/Th e_Energy_Report.pdf?1345748859.

[13] "The Science of Sustainability," The Nature Conservancy October 14, 2018.

[14] A. Harder, "Environmental Groups Change Tune on Nuclear Power," WSJ Jun 16, 2018.

[15] A. S. Bisconti, "Public opinion on nuclear energy: what influences it," Bulletin of the Atomic Scientists 2016.

[16] R. Riffkin, "For first time, majority in US oppose nuclear energy," 2016. Retrieved from Gallup: http://www. Gallup. com/poll/190064/first-time-majority-oppose-nuclear-energy. aspx.

[17] J. Bowden, "Americans evenly split on nuclear power: poll," The Hill March 27, 2019.

[18] Informed Public Attitudes towards Fusion Energy in Europe. Eurofusion April 2019.

[19] D. Wojick, "Dominion Energy proposes $40 \%$ rate hike in Virginia to pay for "net zero carbon." Cost/CFACT.ORG May 23, 2020.
[20] Management Information Services, Inc. and Leonardo Technologies Inc., "Economic Impact Assessment of CCUS Retrofit of the Comanche Generating Station," prepared for the U.S. Department of Energy and the National Energy Technology Laboratory, June 2019.

[21] G. L. Kulcinski and R. W. Conn, "The Conceptual Design of a Tokamak Power Reactor," UWMAK-I. UWFDM-90. April 1974.

[22] F. Najmabadi. "ARIES-AT: An Advanced Tokamak, Advanced Technology Fusion Power Plant," Fusion Engineering and Design 80, 3-23, 2006.

[23] D. Maisonnier, D. Campbell, I. Cook, L. Di Pace, L. Giancarli, J. Hayward, A. Li Puma, M. Medrano, P. Norajitra and M. Roccella, "Power plant conceptual studies in Europe," Nuclear Fusion 47, 15241532, 2007.

[24] L. J. Perkins, "Fusion - The Competition and the Need for Advanced Concepts," LLNL September 22, 1993 \& March 30, 1994.

[25] B. Bigot, "ITER, An Update on Project Progress," Fusion Power Associates Annual Meeting, December 7, 2017.

[26] Fusion Energy - Actions Needed to Finalize Cost and Schedule Estimates for U.S. Contributions to an International Experimental Reactor. GAO-14-499. June 2014.

[27] D. L. Jassby. "Fusion Reactors Share Seven Drawbacks of Fission Reactors," Physics and Society October 2016.

[28] R. L. Hirsch, G. L. Kulcinski, D. Chapin, and H. Diekamp, "Likely US Regulatory Considerations for DT Fusion Power Reactors," Fusion Science and Technology, 76(5), 670-679, 2020.

[29] D. Schissel, B. Biewald. "Nuclear Power Construction Costs. Synapse Energy Economics," EIA. Capital Cost Estimates for Utility Scale Electricity Generating Plants July 2008.

[30] W. Rod "Vogtle Cost Upgrade Causes Rethinking of \$25B Nuclear Plant's Future," Power Engineering 16 August 2018.

[31] "Plant Investment for Nuclear Power Projects," Atomic Energy Commission, Annual Financial Report, 1959.

[32] K. D. Nichols, "The Road to Trinity: A Personal Account of How America's Nuclear Policies Were Made," New York: William Morrow and Company 1987.

[33] L. Irlam, "Global costs of carbon capture and storage," Global CCS institute 2017.

[34] O.Crofts, "Maintenance duration estimate for a DEMO fusion power plant, based on the EFDA WP12 pre-conceptual studies," Fusion Engineering and Design, Oct. 214. L. Farquhar, Parametric modeling of EU-Demp remote maintenance strategies and concepts, Fusion Engineering and Design, Aug. 2019. 